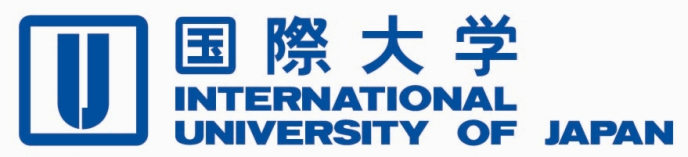

Economics \& Management Series

EMS-2012-19

\title{
Fiscal Stimulus and Labor Market Dynamics in Japan
}

Ryuta Ray Kato

International University of Japan

\author{
Hiroaki Miyamoto \\ International University of Japan
}

November 2012

IUJ Research Institute

International University of Japan

These working papers are preliminary research documents published by the IUJ research institute. To facilitate prompt distribution, they have not been formally reviewed and edited. They are circulated in order to stimulate discussion and critical comment and may be revised. The views and interpretations expressed in these papers are those of the author(s). It is expected that the working papers will be published in some other form. 


\title{
Fiscal Stimulus and Labor Market Dynamics in Japan
}

\author{
Ryuta Ray Kato and Hiroaki Miyamoto* \\ International University of Japan
}

November 11, 2012

\begin{abstract}
The paper studies effects of fiscal expansion on the Japanese labor market. First, using a structural VAR model, we find that the unemployment rate falls and employment rises following an increase in government spending. We also find that fiscal expansion affects flows in and out of unemployment. While an increase in government spending increases the job-finding rate, it reduces the separation rate. We then incorporate search and matching frictions into a standard dynamic general equilibrium model, and study whether the model can explain what we observed in data. While the model fails to predict the exact size of the impact of the government spending shock on the Japanese labor market variables, it can consistently capture the empirical pattern of responses of labor market variables to the shock.
\end{abstract}

JEL Classification: E24; E62; J64

Keywords: Fiscal Policy; Unemployment; Labor market; Search and matching

*Corresponding Address: Hiroaki Miyamoto, hmiyamot@iuj.ac.jp, 777 Kokusai-cho, Minami Uonuma-shi, Niigata 949-7277 JAPAN, TEL., +81-25-779-1464, FAX., +81-25-779-1187. Part of this research is supported by the Grants-in-Aid for Young Scientists of the Japan Society for the Promotion of Science (No. 24730179). 


\section{Introduction}

An important objective of fiscal policies is to boost output and to reduce unemployment in recessions. It is crucial to understand the effects of fiscal policies, such as government spending on employment and unemployment, both empirically and theoretically. While there is an active debate on the effects of fiscal policies on the labor market among policy makers, the debate on fiscal policies among economists has rather focused on the size of the output and consumption multipliers of government spending. Recently, a number of studies investigate the effects of government spending on labor market variables (Yuan and Li, 2000; Monacelli et al. 2010; Brückner and Pappa, 2012). However, these studies mainly focus on the U.S., and less is known about the effects of fiscal expansion on labor markets in the other countries. Especially, there has no study on the Japanese case. Given the fact that Japan's budget deficits and public debts have grown through fiscal stimulus spending and also that Japan is the most indebted nation among OECD countries, it is crucial to examine the effectiveness of fiscal policies in the Japanese economy. ${ }^{1}$ In this paper, we study the effects of government spending on labor market dynamics in the Japanese economy both empirically and theoretically.

Recently, Brückner and Pappa (2012) find that a fiscal expansion can lead to a significant increase in unemployment for many OECD countries by using a structural VAR model. Their seemingly paradoxical result has led to reconsideration of the impact of government spending on the labor market in the RBC and the New Keynesian models (Faia et. al. forthcoming). In the first part of our analysis, we thus examine the effects of government spending on the Japan's labor market by using structural VAR models ${ }^{2}$, to investigate to the extent how much the paradoxical result holds in Japan. In order to provide a detail on the transmission of fiscal policy to the labor market, we study the effects on variables such as the unemployment rate, inflow and outflow rates of unemployment, the intensive and extensive margins of work, labor force participation, vacancies, and the real wage. In contrast to Brükner and Pappa (2012), our empirical analysis demonstrates that an increase in government spending increases employment and vacancies posted, and reduce unemployment. These responses are accompanied by an increased outflow rate of unemployment and a decreased inflow rate of unemployment.

In the second part of our analysis, we develop a stochastic dynamic general equilibrium

\footnotetext{
${ }^{1}$ Through a combination of fiscal stimulus spending and increasing social security payouts, gross public debt has exceeded $216 \%$ of GDP as of 2010 in Japan.

${ }^{2} \mathrm{~A}$ number of studies investigate the effect of fiscal policy on macroeconomic variables such as output, private consumption, and private investment in Japan (Ramaswamy and Rendu, 2000; Kamoi and Tachibanaki, 2001; Kato, 2001; Kuttner and Posen, 2001; Ihori et al., 2002; Tanaka and Kitano, 2002; Ihori et al., 2003; Kato, 2003; Nakazato and Konishi, 2004; Kitaura et al., 2005).
} 
model with search frictions in the labor market and study the effect of government spending on labor market variables. Specifically, we incorporate search and matching frictions à la Mortensen and Pissarides (1994) into an otherwise standard real business cycle model. The parameters in the model are calibrated to match certain facts of the Japanese economy.

Our model can generate a similar pattern of responses of labor market variables to government spending shock to that of SVAR models. The numerical analysis demonstrates that a positive government spending shock leads to a significant fall in the unemployment rate and increases in both vacancies and employment. However, our model fails to trace empirical responses of private consumption to government spending shocks, as seen in the standard neoclassical model. ${ }^{3}$ While private consumption rises in response to a positive government spending shock in the data, it falls in the model. This is due to a negative wealth effect; since higher government spending is financed by higher taxes, a household reduces their consumption as consumption is normal goods.

While our model can qualitatively capture the empirical responses of labor market variables to a government spending shock, it quantitatively fails to predict the size of the impact of government spending on labor market variables. ${ }^{4}$ While the unemployment rate falls by about 0.003 points at the peak in the model, it falls by about 0.014 points at the peak in our SVAR estimates. The size of the impact on vacancies is also too small: The calculated value of a rise in the model is about 0.01 points at the peak, which is much less than our SVAR estimates.

This study is related to the recent literature on fiscal effects on the labor market. Monacelli et al. (2010) studies the effects of fiscal policy on the U.S. labor market. Monacelli et al. (2010) examine the effects fiscal policy on the labor market by developing a standard dynamic general equilibrium model with search friction and non-separable utility in consumption and leisure neglecting adjustment over the intensive margin. In contrast, our model allows for an intensive margin of labor adjustment, since it is known that the intensive margin accounts for much of total worked variation in Japan. ${ }^{5}$ In order to examine the effect of fiscal policy on the U.S. labor market, Yuan and Li (2000) develop a stochastic general equilibrium model with search frictions and both intensive and extensive margins. While in their model, labor supply decision is determined by households, in our model, hours worked are determined through bargaining

\footnotetext{
${ }^{3}$ See for example Baxter and King (1993).

${ }^{4}$ The search and matching model has been recently criticized for its inability in tracing observed unemployment and vacancy fluctuations in response to the reasonable productivity shock. See Shimer (2005), Hall (2005), Mortensen and Nagypál (2007), and Pissarides (2009).

${ }^{5}$ While the extensive margin mainly accounts for the overall variability in total hours worked in the U.S and European countries, the intensive margin accounts for much of total hours worked variation in Japan. See Kakinaka and Miyamoto (2012) for the detail.
} 
between firms and workers. Brückner and Pappa (2012) find that for many OECD countries, positive government spending shocks increase the unemployment rate significantly by using structural VAR models and then explain the facts by using a standard New Keynesian model with search frictions and workers' labor participation choices. In contrast to their studies, we show that an increase in government spending reduces the unemployment rate in Japan.

This paper is also related to the recent literature on effects of fiscal policies in the Japanese economy. A number of studies assess the effects of fiscal policy in Japan using dynamic stochastic general equilibrium models (Iwata, 2009; Fueki et al., 2011). While they focus on the effects of fiscal policy on macroeconomic variables such as output, consumption and investment, we focus on the effects of fiscal policy on the labor market. Thus, this paper complements these previous studies by investigating the effects of fiscal policy on labor market dynamics.

The reminder of the paper is organized as follows. Section 2 presents the empirical results from structural VAR models. Section 3 develops a stochastic general equilibrium model with search frictions in the labor market. In section 4, we calibrate the model parameters and present the quantitative results of effects of fiscal expansion on the labor market. Section 5 discusses the sensitivity of the numerical results to our choice or parameters. We also examine how the degree of persistence of government spending shocks affects predictions of the model. Section 6 concludes.

\section{Empirical Evidence}

In this section, we empirically study effects of government spending shocks on labor market variables by using a structural vector autoregressive model (VAR). Following Blanchard and Perotti (2002), we identify a government spending shock by assuming that government spending is predetermined relative to other variables and does not react contemporaneously to output and other shocks. ${ }^{67}$ This identification scheme is implemented by ordering government spending first in a VAR model and using a Choleski decomposition.

For benchmark specification, we consider a VAR model consisting of seven variables: government spending, gross domestic product (GDP), private consumption, private investment,

\footnotetext{
${ }^{6}$ Gali et al. (2007) and Perotti (2007) also use the restriction that government spending does not contemporaneously react to changes in macroeconomic variables to identify fiscal shocks. On the other hand, Ramey and Shapiro (1998) and Burnside et al. (2004) identify fiscal shocks as episodes of significant exogenous and unforeseen increases in defense spending. These two approaches yield different results on the effects of government spending on consumption. See Perotti (2007) for the detail.

${ }^{7}$ Monacelli et at. (2010) and Brückner and Pappa (2012) also use this identification approach to investigate the effect of government spending on the labor market.
} 
real wages, the short-term interest rate, the tax revenues. ${ }^{8}$ Except the interest rate and real wages, all other variables are in real per capita terms. We obtain quarterly data on government spending, GDP, private consumption, private investment, and the tax revenues from the Cabinet Office. The short-term interest rate are obtained from the Bank of Japan Statistics and the real wages are taken from Monthly Labour Survey conducted by the Ministry of Health, Labour and Welfare.

Following Monacelli et al., (2010), we add one or two labor market variables in turn to the fixed set of variables. Specifically, we are interested in labor market variables: employment, unemployment, labor force, hours worked per worker, the vacancy rate, the job-finding rate, and the separation rate.

All variables are seasonally adjusted by using the X12-filter and enter the VAR models as logdeviations from a constant and linear and quadratic time trends. ${ }^{9}$ The sample covers 1985Q42010Q1. The lag length of VAR models is based on information criteria and set equal to one.

In the first specification, we incorporate the logs of employment and hours worked per worker. The impulse responses of the relevant variables to a government spending shock are shown in Figure 1. The shock is a one standard error shock to government spending, and the impulse responses are shown with $95 \%$ confidence bands constructed by Monte Carlo simulations. We show the response functions for a horizon of 20 quarters.

An increase in the government spending have significant positive effects on GDP and private consumption. On the impact, GDP rises and reaches its peak after one and a half years. The government spending shock generates a crowding-in of private consumption. After the shock, private consumption increases immediately and contributes to an output rise. Investment falls initially and rises after 1 quarter, but the response is not significant for all horizons after the government spending shock. These results are broadly consistent with what previous studies found. ${ }^{10}$

We now see the effect of the government spending shock on labor market variables. Employment rises significantly and reaches its peak after about 9 quarters. An increase in government spending has a negative effect on hours per worker. Hours worked falls by about 0.11 percentage points at peak and the response is significant at the peak.

\footnotetext{
${ }^{8}$ Basically our model specification follows existing empirical work that studies effects of fiscal policies in the Japanese economy by using VAR models. Kawade et al. (2004) survey the empirical studies that examine effects of fiscal policies in Japan by using VAR models.

${ }^{9}$ We have checked the robustness of our estimates using structural VAR models with detrended variables with HP filter, instead of using log-deviations from a constant and a quadratic time trend. Basically, the results are the same.

${ }^{10}$ See footnote 1.
} 

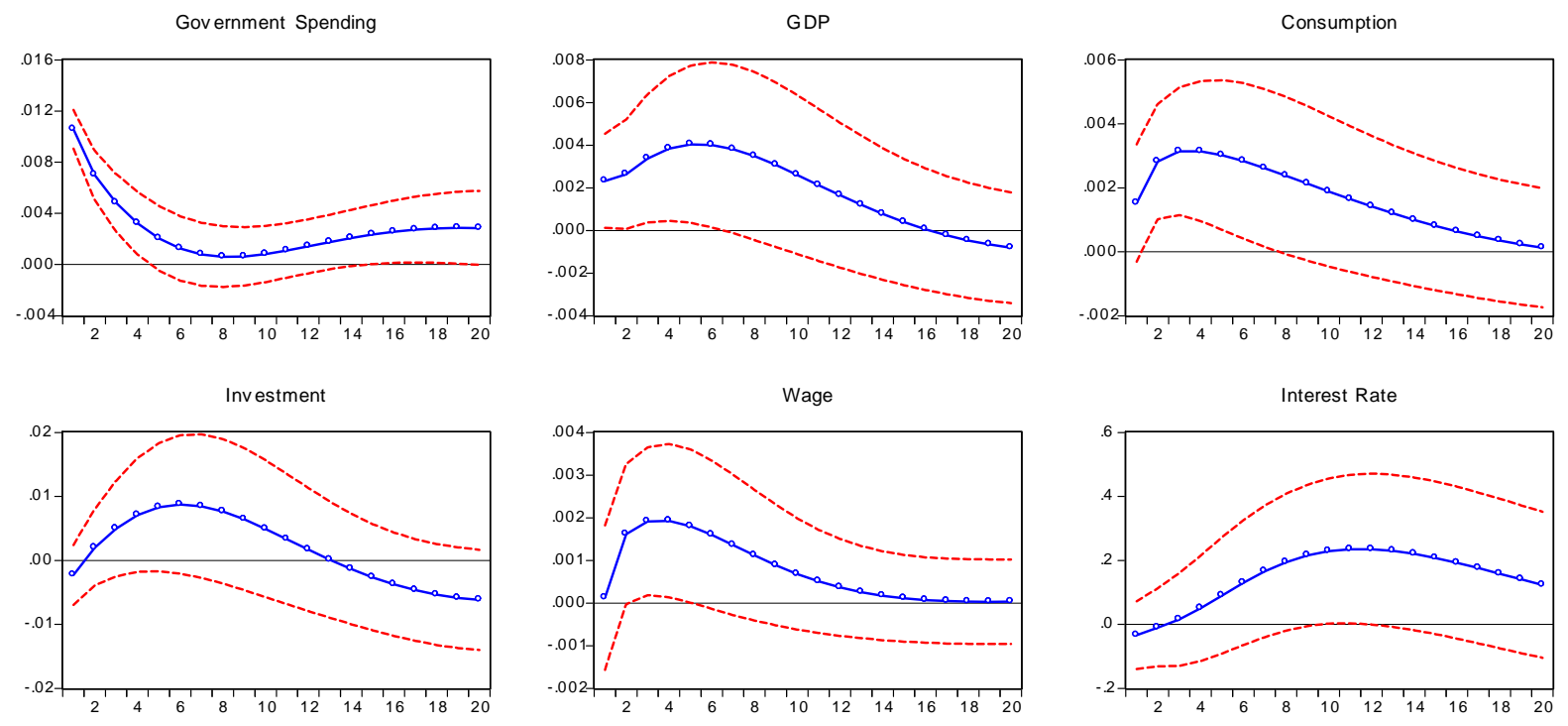

Tax Revenue
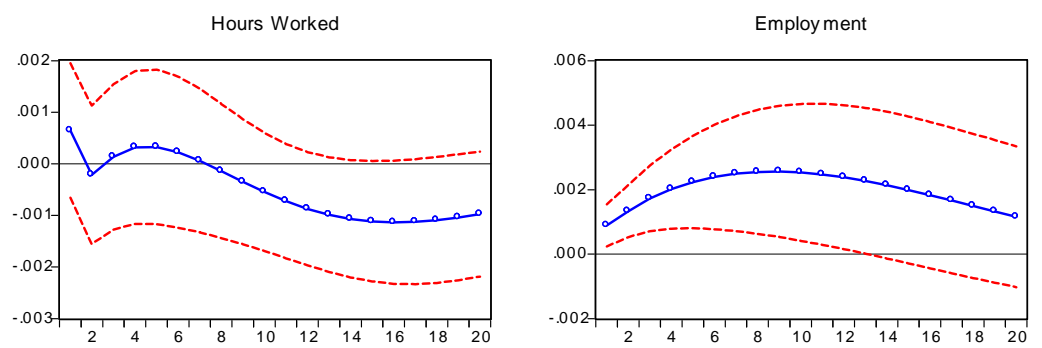

Figure 1: Estimated impulse responses from the VAR.

Note: Dashed-lines indicate the $95 \%$ confidence bands constructed by Monte Carlo simulations. 
In the second specification, we add both the logs of the labor force and unemployment (both divided by population) to the fixed set of variables. Figures 2 (a)-(b) show the response of these two variables to the government spending shock. The labor force increases by about 0.1 percentage points at peak and it is significant. However, in general, the labor force does not move significantly. Unemployment response to the government spending shock is negative. It falls by about 1.4 percentage points at peak. In order to examine the robustness of the results, we now incorporate the unemployment rate, instead of unemployment and labor force, to the fixed set of variables. The result is presented in Figure 2-(c). The government spending shock has a negative effect on the unemployment rate.

Next, we add both the logs of vacancies and of unemployment into the fixed set of variables. The measure of job vacancies is obtained from the monthly Report on Employment Service (Shokugyo Antei Gyomu Tokei) conducted by the Ministry of Health, Labour and Welfare. ${ }^{11}$ Note that the Report on Employment Service is an administrative data set and it measures only a number of firms that post advertisements at the Employment Agency to find workers. Job vacancies are defined as the difference between the number of active job openings (yuko-kyuujinsuu) and the number of job placements (shushoku-ken-suu). As seen in Figure 2-(d), vacancies rises substantially with peak responses at about 2.6 percent after 6 quarters.

Dynamics of the unemployment rate are determined by the underlying flows in and outs of unemployment, particularly the rates at which workers match with and separation from jobs. ${ }^{12}$ We now study the responses of the job finding rate and of the separation rate to the government spending shock. We add the job finding rate and the separation rate to our fixed set of variables in turn. Following Miyamoto (2011), we construct the job-finding rate and the separation rate from the Labour Force Survey (LFS) conducted by the Statistics Bureau and the Director-General for Policy Planning.

Figure 2 (e)-(f) presents the results. The job finding rate initially falls and rises after 3 quarters. The separation rate falls by about 1.6 percentage point at the peak. The responses of the job-finding and separation rates are consistent with the response of the unemployment rate to the government spending shock.

\footnotetext{
${ }^{11}$ It is important to note that job vacancies are not measured on the same basis as economy-wide unemployment. Although the data on vacancies are not perfect, this study uses this data source because it is the only available data that covers long periods consistently. Please see Miyamoto (2011) for the detail.

${ }^{12}$ In this paper, we define the job finding rate as the rate of transition from unemployment to employment, and the separation rate as the rate of transition from employment to unemployment.
} 

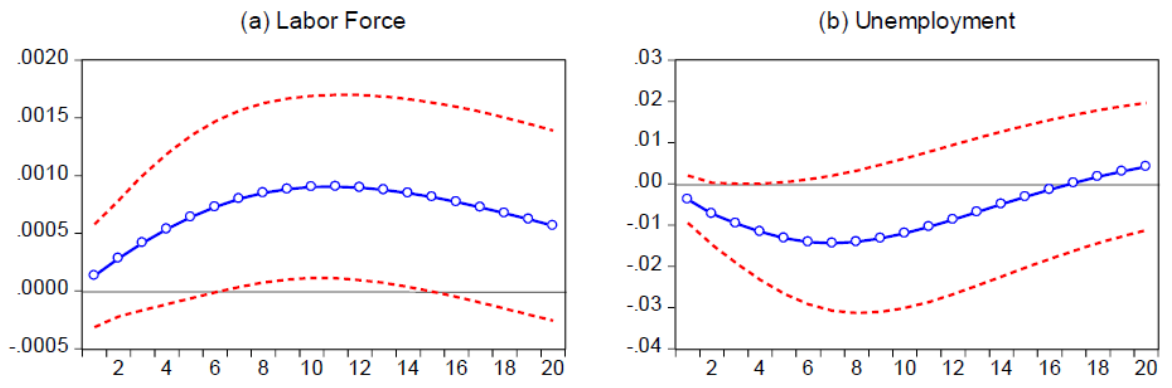

(c) Unemployment Rate

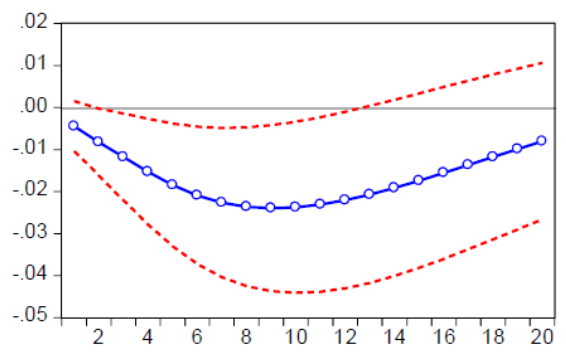

(d) Vacancies

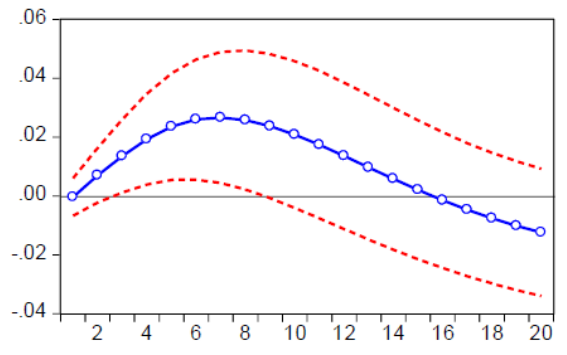

(e) Job-finding Rate

(f) Separation Rate
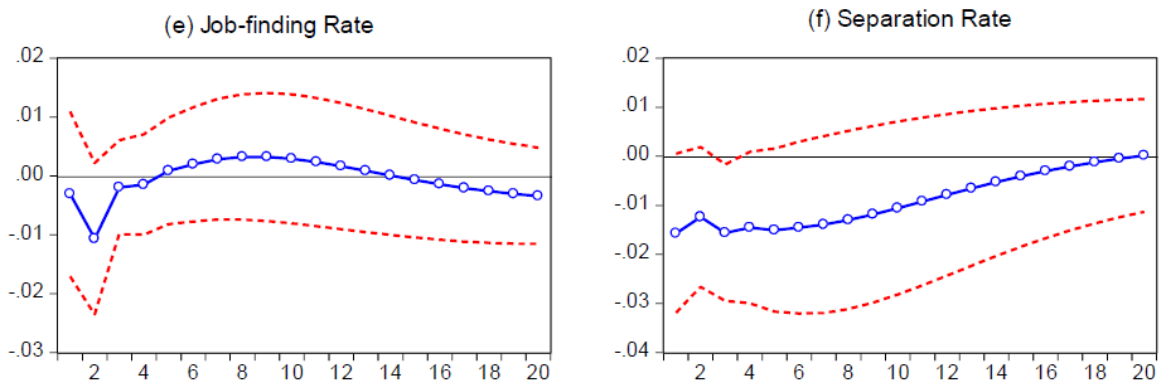

Figure 2: Estimated impulse responses of labor market variables from the VAR

Note: Dashed-lines indicate the $95 \%$ confidence bands constructed by Monte Carlo simulations. 


\section{The Model}

We consider a stochastic dynamic general equilibrium model with search frictions in the labor market. ${ }^{13}$ An economy consists of households, firms, and the government. Each household consists of a continuum of infinitely-lived workers normalized to one. They search for jobs when unemployed, while they supply labor services and earn wages when employed. Firms hire workers in a frictional labor market and produce outputs by using capital and labor. Firms sell their products to households in a competitive market. Employment is the outcome of workers' and firms' search behavior, while wages and labor supply are outcome of a bargaining process. Time is discrete.

Labor market The labor market is subject to frictions and firms and workers cannot meet instantaneously but must go through a time-consuming search process. The labor market is modeled in the style of a search and matching model developed by Mortensen and Pissarides (1994). The number of successful job matches is determined by the Cobb-Douglas matching function

$$
m\left(u_{t}, v_{t}\right)=\gamma_{m} u_{t}^{\xi} v_{t}^{1-\xi}
$$

where the parameter $\gamma_{m}>0$ represents the efficiency of the matching process, $u_{t}$ is the number of unemployed workers and $v_{t}$ is the number of vacancies, and $0<\xi<1$ is the elasticity of the matching function with respect to unemployment. Define $\theta_{t} \equiv v_{t} / u_{t}$, as labor market tightness. The probability of a firm with a vacancy is matched with a worker is given by $m\left(u_{t}, v_{t}\right) / v_{t}=\gamma_{m} \theta_{t}^{-\xi} \equiv q\left(\theta_{t}\right)$. Similarly, the probability that an unemployed worker is matched is $m\left(u_{t}, v_{t}\right) / u_{t}=\gamma_{m} \theta_{t}^{1-\xi}=p\left(\theta_{t}\right)$. Note that both firms and workers take $q_{t}$ and $p_{t}$ as given.

Matches are destroyed at an exogenous rate $s$ which takes place at the end of period $t$. We assume that it takes one period for new matches to be productive and that both old and new matches faces the same separation rate. ${ }^{14}$ The evolution of employed workers, defined as $n_{t}=$ $1-u_{t}$, is given by

$$
n_{t}=(1-s)\left[n_{t-1}+m_{t-1}\right]
$$

Thus, the number of employed workers at time $t$ is given by the number of employed worker at time $t-1$ plus new matches formed in period $t$ that were not destroyed.

Household's problem A representative household consists of a continuum of individuals of mass one. A member of the household is either employed or unemployed. In the period $t$, a

\footnotetext{
${ }^{13}$ Andolfatto (1996) and Merz (1995) consider a stochastic real business cycle model with search and matching frictions.

${ }^{14}$ This timing assumption is adopted in search and matching models. See for example, Lubik (2009).
} 
fraction $n_{t}$ of the household's members are employed and, a fraction of $u_{t}$ are employed. The household pools incomes and share total income and risk among all family members as in Merz (1995).

The preference of the representative household is given by

$$
\max _{\left\{c_{t}, k_{t+1}\right\}} \mathbb{E}_{0} \sum_{t=0}^{\infty} \beta^{t}\left[\frac{C_{t}^{1-\sigma}}{1-\sigma}-\Phi n_{t} \frac{h_{t}^{1+\mu}}{1+\mu}\right],
$$

where $\beta \in(0,1)$ is the household's subjective discount factor, $C_{t}$ is consumption, and $h_{t}$ is the individual hours worked and $\Phi>0$ measures the disutility of working, $\mu$ is the inverse of the Frisch elasticity of labor supply, and $1 / \sigma$ is the intertemporal elasticity of substitution.

Employed household members earn wage $w$ and unemployed household members receive unemployment benefits $z$. The household receive profits from the firms $\Pi$ and pays lump sum taxes to the government $T$. The household may either consume $C$ which is an aggregate consumption of the household or accumulate capital $K$ through investment $I$ according to

$$
K_{t+1}=(1-\delta) K_{t}+I_{t}
$$

where $\delta$ is the depreciation rate.

The budget constraint of the representative household is

$$
C_{t}+K_{t+1}=w_{t} n_{t} h_{t}+\left(1-n_{t}\right) z+r_{t} K_{t}+(1-\delta) K_{t}+\Pi_{t}-T_{t}
$$

where $r_{t}$ denotes the real rental rate of capital. In addition, the household recognized that employment is determined by the law of motion (1).

The household's problem yields the following first-order conditions

$$
C_{t}^{-\sigma}=\lambda_{t}
$$

and

$$
\beta \mathbb{E}_{t} \lambda_{t+1}\left[1+r_{t+1}-\delta\right]=\lambda_{t}
$$

where $\lambda_{t}$ is the Lagrange multiplier on the budget constraint. These first-order conditions yield the following Euler equation

$$
\beta \mathbb{E}_{t} C_{t+1}^{-\sigma}\left[1+r_{t+1}-\delta\right]=C_{t}^{-\sigma}
$$

Firm's problem When a firm hires a worker, the firm produces output according to a constant returns to scale production function $y_{t}=A_{t} f_{t}\left(k_{t}, h_{t}\right)$ where $A_{t}$ is a technology factor common to all firms, $k_{t}$ is capital, and $h_{t}$ is hours worked per worker. 
The problems of firms and workers are characterized by the Bellman equations. The value for a firm with a filled job, $\mathcal{J}_{t}$, is characterized by the following Bellman equation:

$$
\mathcal{J}_{t}=\max _{k_{t}}\left\{A_{t} f\left(k_{t}, h_{t}\right)-w_{t}\left(h_{t}\right) h_{t}-r_{t} k_{t}+\beta \mathbb{E}_{t} \frac{\lambda_{t+1}}{\lambda_{t}}\left[(1-s) \mathcal{J}_{t+1}+s \mathcal{V}_{t+1}\right]\right\}
$$

where $\mathcal{V}_{t}$ is the value of a firm with a vacant job. The value of a firm with a filled job is current profits plus the continuation value. In the current period, the firm produces $A_{t} f\left(k_{t}, h_{t}\right)$ and pays wage $w_{t}\left(h_{t}\right) h_{t}$ and the rental cost of capital $r_{t} k_{t}$. In the next period, if the match is not destroyed, which occurs with probability $(1-s)$, the firm obtains the future expected value of a job $\mathcal{J}_{t+1}$, otherwise the match is destroyed and becomes a vacancy. The expected future value of the job is discounted by the stochastic discount factor $\beta \lambda_{t+1} / \lambda_{t}$.

The first-order condition for the capital is

$$
A_{t} f_{k}\left(k_{t}, h_{t}\right)=r_{t}
$$

This implies that the optimal capital is chosen to equate the marginal product of capital to the rental rate.

The value of a firm with a vacant job is

$$
\mathcal{V}_{t}=-\kappa+\beta \mathbb{E}_{t}\left\{\frac{\lambda_{t+1}}{\lambda_{t}} q\left(\theta_{t}\right)(1-s) \mathcal{J}_{t+1}+\left[1-q\left(\theta_{t}\right)(1-s)\right] \mathcal{V}_{t+1}\right\}
$$

where $\kappa$ is a flow cost of positing a vacancy. A firm incurs cost $\kappa$ for posting a vacancy and matches with a worker with probability $q\left(\theta_{t}\right)$. If the match is not destroyed, the firm obtains the value of a filled job in the following period; otherwise it remains as a vacancy.

The total profits of the firms are defined as

$$
\Pi_{t}=\left[A_{t} f\left(k_{t}, h_{t}\right)-w_{t}\left(h_{t}\right) h_{t}-r_{t} k_{t}\right] n_{t}-\kappa v_{t} .
$$

In equilibrium, all profit opportunities from new jobs are exploited, so that the following free entry condition holds:

$$
\mathcal{V}_{t}=0
$$

By using the free entry condition, (3) can be rewritten as

$$
\frac{\kappa}{q\left(\theta_{t}\right)}=\beta(1-s) \mathbb{E}_{t}\left\{\frac{\lambda_{t+1}}{\lambda_{t}} \mathcal{J}_{t+1}\right\}
$$

By using this, the value function of $\mathcal{J}$ can be rewritten as

$$
\mathcal{J}_{t}=A_{t} f\left(k_{t}, h_{t}\right)-w_{t}\left(h_{t}\right) h_{t}-r_{t} k_{t}+\frac{\kappa}{q_{t}}
$$


Thus, we have the following job creation condition

$$
\frac{\kappa}{q_{t}}=\beta(1-s) \mathbb{E}_{t} \frac{\lambda_{t+1}}{\lambda_{t}}\left\{A_{t+1} f\left(k_{t+1}, h_{t+1}\right)-w_{t+1}\left(h_{t+1}\right) h_{t+1}-r_{t+1} k_{t+1}+\frac{\kappa}{q_{t+1}}\right\} .
$$

The job creation condition states that expected cost of positing a vacancy, the left-hand side of (4), is equal to the firm's share of the expected new surplus from a new job match, the right-hand side of (4).

Worker's problem We now turn to the worker's side. Let $\mathcal{W}_{t}$ be the value of an employed worker. The value of an employed worker is characterized by the following Bellman equation:

$$
\mathcal{W}_{t}=w_{t} h_{t}-\frac{g\left(h_{t}\right)}{\lambda_{t}}+\beta \mathbb{E}_{t} \frac{\lambda_{t+1}}{\lambda_{t}}\left[(1-s) \mathcal{W}_{t+1}+s \mathcal{U}_{t+1}\right]
$$

where $\mathcal{U}_{t+1}$ is the value of an unemployed worker and $g\left(h_{t}\right) / \lambda_{t} \equiv \Phi h_{t}^{1+\mu} / \lambda_{t}(1+\mu)$ is the disutility from supplying labor in terms of consumption. The value of an employed worker is composed of the wage, the disutility from supplying labor, and the continuation value, which is the value of being employed if the match is not destroyed, or the value of being unemployed if it is destroyed.

The value of an unemployed worker is

$$
\mathcal{U}_{t}=z+\beta \mathbb{E}_{t} \frac{\lambda_{t+1}}{\lambda_{t}}\left[p_{t}(1-s) \mathcal{W}_{t+1}+\left[1-p_{t}(1-s)\right] \mathcal{U}_{t+1}\right]
$$

where $z$ is the unemployment benefit. In the current period, an unemployed worker receives the unemployment benefit $z$, and matches with a firm with a vacant job with probability $p_{t}$. If the match is not destroyed, the worker becomes productive in the following period and obtains the value of being employed; otherwise, she remains unemployed and obtains the value of being unemployed.

Wage bargaining and hours choice Wages and hours worked are determined as the outcome of a bilateral bargaining process between workers and firms. In each period, firms and workers negotiate through Nash bargains. Thus, wage and hours worked are chosen to maximizes the Nash product

$$
\max _{w_{t}, h_{t}}\left(\mathcal{W}_{t}-\mathcal{U}_{t}\right)^{\eta}\left(\mathcal{J}_{t}-\mathcal{V}_{t}\right)^{1-\eta},
$$

where $\eta \in(0,1)$ is a worker's bargaining power.

Taking first-order conditions with respect to $w$ and $h$, we have the wage equation

$$
w_{t} h_{t}=\eta\left(A_{t} f\left(k_{t}, h_{t}\right)-r_{t} k_{t}+\kappa \theta_{t}\right)+(1-\eta)\left(\frac{g\left(h_{t}\right)}{\lambda_{t}}+z\right)
$$


and the hours supply equation

$$
A_{t} f_{h}\left(k_{t}, h_{t}\right)=\frac{g^{\prime}\left(h_{t}\right)}{\lambda_{t}} .
$$

The wage equation is similar to the one in the search and matching literature. ${ }^{15}$ The wage is a weighted average of the marginal revenue product and the cost of replacing the worker, and of the outside option of the worker, which consists of unemployment benefits and the marginal disutility of labor.

The hours supply equation states that hours worked is determined by equalizing the marginal product of hours and the worker's marginal rate of substitution between leisure and consumption.

Government policy and resource constraint The government has to finance government spending $G_{t}$ and unemployment benefits $u_{t} z$ by imposing the lump-sum tax $T_{t}$ to households. The government budget constraint is thus given by

$$
T_{t}=G_{t}+u_{t} z
$$

The government spending, $G_{t}$, follows the exogenous stochastic process:

$$
\log \left(G_{t}\right)=\left(1-\rho_{G}\right) \log (G)+\rho_{G} \log \left(G_{t-1}\right)+\varepsilon_{G, t},
$$

where $\varepsilon_{G, t}$ i.i.d. and $G$ denotes the steady-state share of government spending.

Aggregate output and capital are obtained by

$$
Y_{t}=n_{t} y_{t}
$$

and

$$
K_{t}=n_{t} k_{t}
$$

respectively.

By combining the household and government budget constraint, we can obtain the aggregate resource constraint. Aggregate production must equal private and public demand:

$$
Y_{t}=C_{t}+I_{t}+G_{t}+\kappa v_{t} .
$$

\footnotetext{
${ }^{15}$ See, for example, Mortensen and Pissarides (1994) and Pissarides (2000) .
} 


\section{Quantitative analysis}

In this section, we simulate a quantitative version of the model. First, we calibrate the model to match several dimensions of the data. We then solve the model by approximating the equilibrium conditions round a non-stochastic steady state and simulate it. ${ }^{16}$

\subsection{Basic calibration}

We calibrate the model to match certain Japanese economy's facts. We choose the model period to be quarter and set the discount rate at $\beta=0.996$. The relative risk aversion parameter $\sigma$ is set to one. We calibrate $\Phi$ such that the implied steady-state value of hours worked is $1 / 3$. The elasticity of intertemporal substitution in the hours supply given by $1 / \mu$, and the value of this elasticity has been the subject of some discussion. Kuroda and Yamamoto (2008) estimate the labor supply elasticity in Japan and find that the elasticity for males is in the range of 0.2 to 0.7 . In our benchmark, we set $\mu$ equal to 2 , which implies a labor supply elasticity of 0.5 .

The matching function is given by $m\left(u_{t}, v_{t}\right)=\gamma_{m} u_{t}^{\xi} v_{t}^{1-\xi}$, where $\gamma_{m}$ is the matching constant and $\xi$ is the matching elasticity with respect to unemployment. Based on Kano and Ohta (2002), we set the elasticity of matching function $\xi=0.6 .{ }^{17}$ This value lies in the plausible range of 0.3-0.5 reported by Petrongolo and Pissarides (2001). We use the Hosios (1990) condition to pin down the worker's bargaining power, so $\eta=\xi$. Miyamoto (2011) reports that the mean values of job-finding and separation rates in Japan are 0.142 and 0.0048 , respectively. ${ }^{18}$ In addition, Miyamoto (2011) reports that the mean value of the vacancy-unemployment ratio is 0.78 . We use the monthly job-finding rate $f=0.142$ and the vacancy-unemployment ratio $\theta=0.78$ to pin down the scale parameter $\gamma_{m}$. We target the monthly separation rate of 0.0048 , which implies the quarterly separation rate of 0.012 .

The production function is specified by $y=k^{\alpha} h^{1-\alpha}$, and we set the capital share $\alpha=1 / 3$. Following Sugo and Ueda (2008) and choose the depreciation rate $\delta$ to equal 0.06 . The vacancy cost function is specified as $c(v)=\kappa v$. Following Shimer (2005), the vacancy cost $\kappa$ is obtained from the steady-state solutions of the model.

We target the unemployment benefits $z$ to be $40 \%$ of the average wage of employed workers in the economy. ${ }^{19}$ Following Iwata (2009), we set the steady-state value for government

\footnotetext{
${ }^{16}$ The log-linearized verison of the model is presented in Appendix.

${ }^{17}$ Kano and Ohta (2002) estimate the matching function in Japanese labor market and obtain the elasticity of matching function $\xi=0.6$.

${ }^{18} \mathrm{By}$ using the panel property of the monthly Labour Force Survey, Miyamoto (2011) constructed the job-finding rate and the separation rate in Japan.

${ }^{19}$ This parameter has been the subject of some discussion. For the U.S labor market, Shimer (2005) sets $z / w=0.4$
} 
spending to output ratio $G / Y=0.16$. Finally, we set the value for the government spending autoregressive parameter $\rho_{g}=0.966$, based on the data. The parameter values are summarized in Table 1.

Table 1: Parameter values

\begin{tabular}{llll}
\hline \hline Parameter & Description & Value & Source/Target \\
\hline$\beta$ & Discount factor & 0.996 & Data \\
$\delta$ & Depreciation rate & 0.06 & Sugo and Ueda (2008) \\
$\alpha$ & Parameter in production function & 0.333 & Data \\
$\gamma_{m}$ & Matching efficiency & 0.471 & Job-finding rate \\
$\xi$ & Matching elasticity & 0.6 & Kano and Ohta (2002) \\
$s$ & Separation rate & 0.012 & Separation rate \\
$\sigma$ & Relative risk aversion parameter & 1.0 & See text \\
$\Phi$ & Disutility of labor & 35.30 & See text \\
$\mu$ & Frisch elasticity & 2.0 & See text \\
$z$ & Unemployment benefits & 0.202 & Replacement rate \\
$\eta$ & Worker's bargaining power & 0.6 & $\eta=\xi$ (efficiency condition) \\
$\kappa$ & Vacancy cost & 0.110 & $v-u$ ratio \\
$\rho_{g}$ & Gov. spending autoregressive parameter & 0.966 & Data \\
\hline
\end{tabular}

Selected endogenous variables in the steady-state under the calibrated parameter are reported in Table 2. The job-finding rate, labor market tightness, hours worked, and the ratio of government spending to output are equal to their target values.

\subsection{Effects of government spending shock}

We now examine the dynamic responses of the economy to government spending shocks. Figure 3 displays the impulse responses of selected variables to a one standard-deviation shock to government spending.

An increase in government spending increases output and hours worked per worker. On the impact, both output and hours worked per worker rise and in the following periods, they decrease and gradually return to their steady-state value. This is due to a negative wealth effect. Since higher government spending is financed by higher taxes, a household increases their labor in order to capture unemployment benefis. Hagedorn and Manovskii (2008) argue that Shimer's value is too low and assume that the flow value of unemployment is much larger and close to productivity level. For the Japan labor market, Miyamoto (2011) sets $z / w$ equal to 0.6 in order to match the replacement ratio, while Esteban-Pretel et al. (2010) set it to 0.4 following Shimer (2005). 

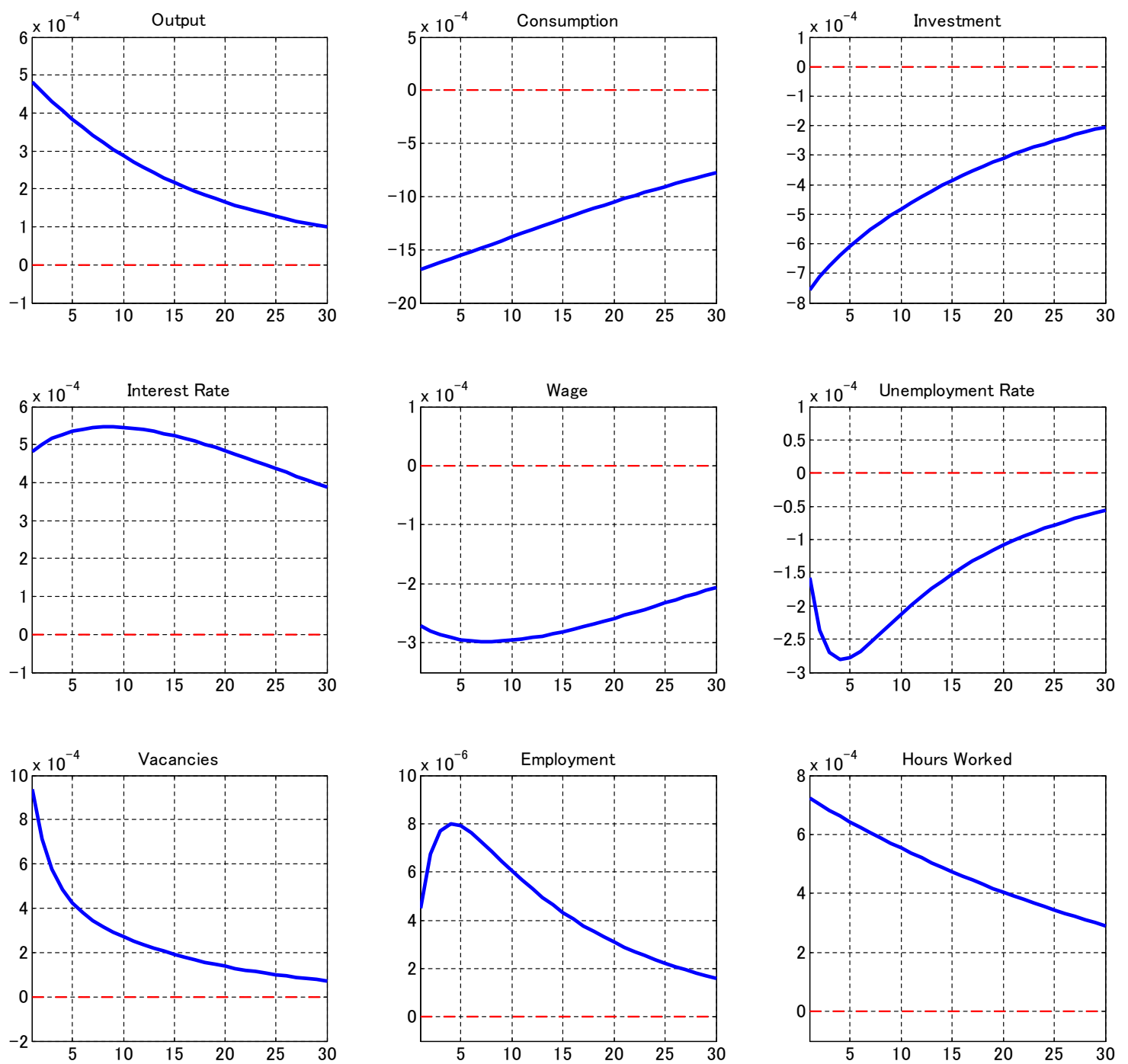

Figure 3: Dynamic responses of the economy to government spending shocks 
Table 2: Model solutions

\begin{tabular}{lll}
\hline \hline Variables & Description & Solution \\
\hline$\theta$ & Labor market tightness & 0.78 \\
$u$ & Unemployment rate & 0.028 \\
$v$ & Vacancy & 0.022 \\
$n$ & Employment rate & 0.972 \\
$p$ & Job-finding rate & 0.426 \\
$h$ & Hours worked & 0.333 \\
$C$ & Aggregate consumption & 0.388 \\
$G$ & Government spending & 0.118 \\
$T$ & Lump-sum tax & 0.124 \\
$Y$ & Aggregate output & 0.740 \\
$I$ & Aggregate investment & 0.231 \\
\hline
\end{tabular}

supply and reduces consumption as consumption and leisure are normal goods. An increase in government spending also crowds out investment. Although our model cannot empirically consistent responses of consumption and investment, the fact that government spending shock crowds out consumption and investment is in line with the prediction of a standard neoclassical model (see, for example, Baxter and King, 1993).

The increase in government spending leads to a significant fall in the unemployment rate and an increase in vacancies. It also increases employment. On the impact, vacancies rise and then gradually return to its steady-state value. The unemployment rate falls and reaches its lowest level in the 4th quarter and then gradually returns to the steady-state value. The response of employment is just opposite to the unemployment rate. Employment rises in the first 4 quarters and then decreases. The pattern of responses of the unemployment rate, vacancies, and employment are in line with what we observed in the data.

These movements in labor market variables are explained as follows. In the model, employment is determined by vacancy postings of firms. A firm decides whether posting a vacancy based on the expected value of hiring a worker. A higher value of hiring a worker encourages the firm to post a vacancy. The value of hiring a worker is the firm's share of the expected new surplus from a new job match, which is basically determined by the stochastic discount factor and the pure economic rent in each period. ${ }^{20}$ While a higher stochastic discount factor leads to a lower value of hiring a worker, a higher economic rent increases the value of hiring a worker.

\footnotetext{
${ }^{20}$ This can be understood by seeing the job creation condition (4).
} 
On one hand, the government spending shock increases the interest rate, and so the stochastic discounting factor. This lowers the value of hiring a worker. On the other hand, the government spending shock increases productivity of the job, leading to a higher value of hir-

ing a worker. Under our calibrated parameters, the latter effect dominates the former one, and firms post more vacancies. As a results, employment rises and the unemployment rate falls.

We have seen that our model qualitatively generates empirically consistent responses of labor market variables to the government spending shock. We now examine whether our model quantitatively generate similar responses of labor market variables to those in our SVAR model. While the unemployment rate falls by about 0.003 at the peak in the model, it falls by about 0.014 at the peak in our SVAR estimates. Thus, the model cannot generate enough magnitude of the response of the unemployment rate to government spending shock. Similarly, the model fails to generate the size of the impact of government spending shock on vacancies. In the model, vacancies rise about 0.01 at the peak, which is much less than our SVAR estimates.

\section{Discussion}

This section evaluates the robustness of our results in the previous section. First, we discuss the sensitivity of the results to our choice of parameter values. We then examine how the degree of persistence of government spending shocks affects predictions of the model.

\subsection{Sensitivity analysis}

In the benchmark case, the model generates empirically consistent patterns of responses of labor market variables to a government spending shock but fails to generate enough magnitude. We now discuss how these results vary with the relative risk aversion parameter $\sigma$, the parameter for the elasticity of intertemporal substitution $\mu$, and the flow value of unemployment $z$. when we change these parameters, we also re-calibrate parameters $\kappa$ and $\Phi$ in order to maintain our calibration target values.

First, we discuss the sensitivity of the results to our choice of the relative risk aversion parameter $\sigma$. The results are shown in Figure 4 . The sensitivity analysis suggests that a larger value of $\sigma$ yields a larger effect of government spending shock on relevant variables. This is because the elasticity of the outside option to consumption increases with a higher value of $\sigma$.

Next, we consider the impact of the parameter for the elasticity of intertemporal substitution $\mu$. Results are shown in Figure 5. The impact of government spending on output and labor market variables shrinks as $\mu$ increases. In our model, the marginal cost of production equals to the marginal rate of substitution between consumption and leisure. An increase in convexity in 

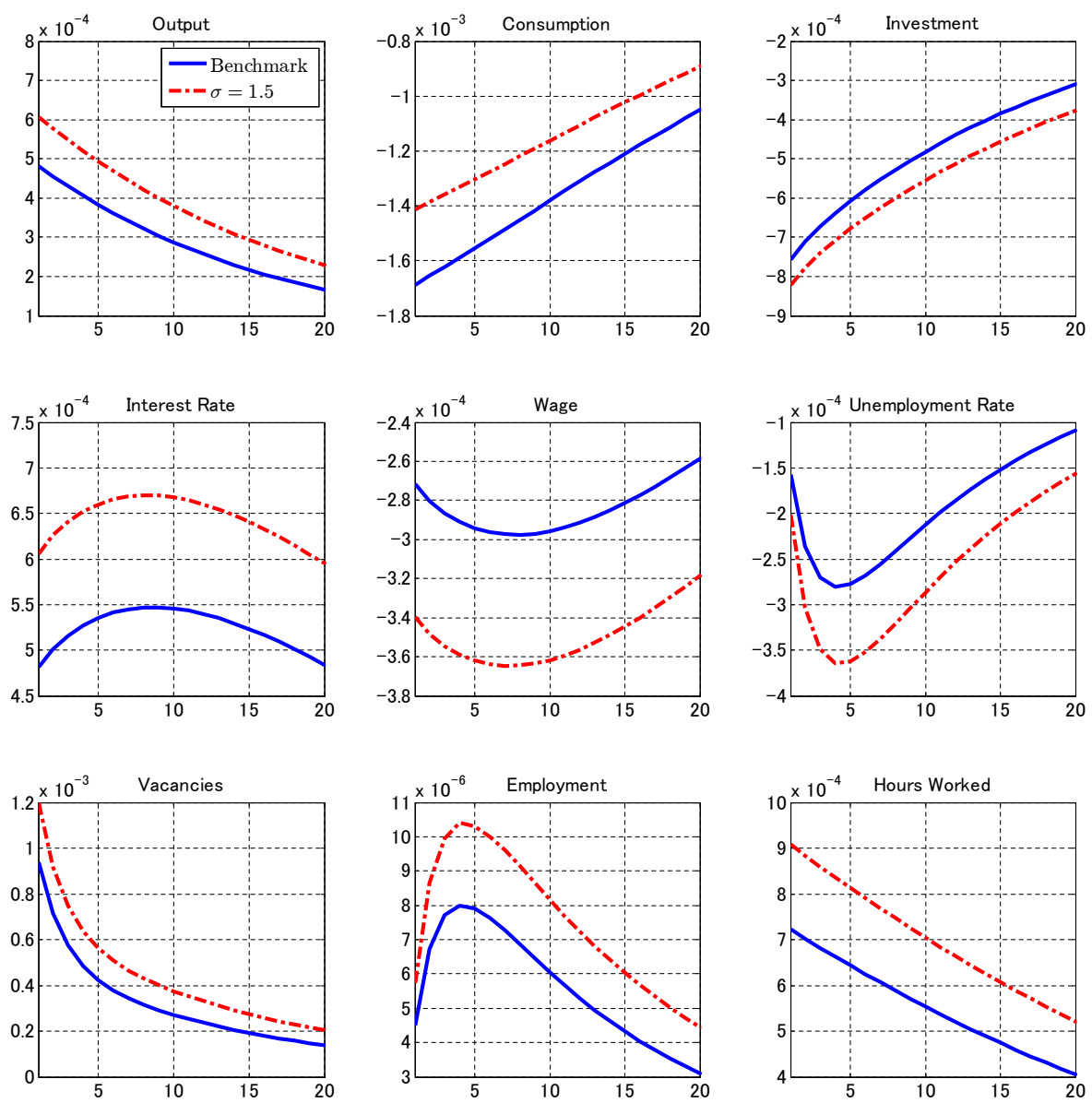

Figure 4: Sensitivity analysis with respect to $\sigma$ 

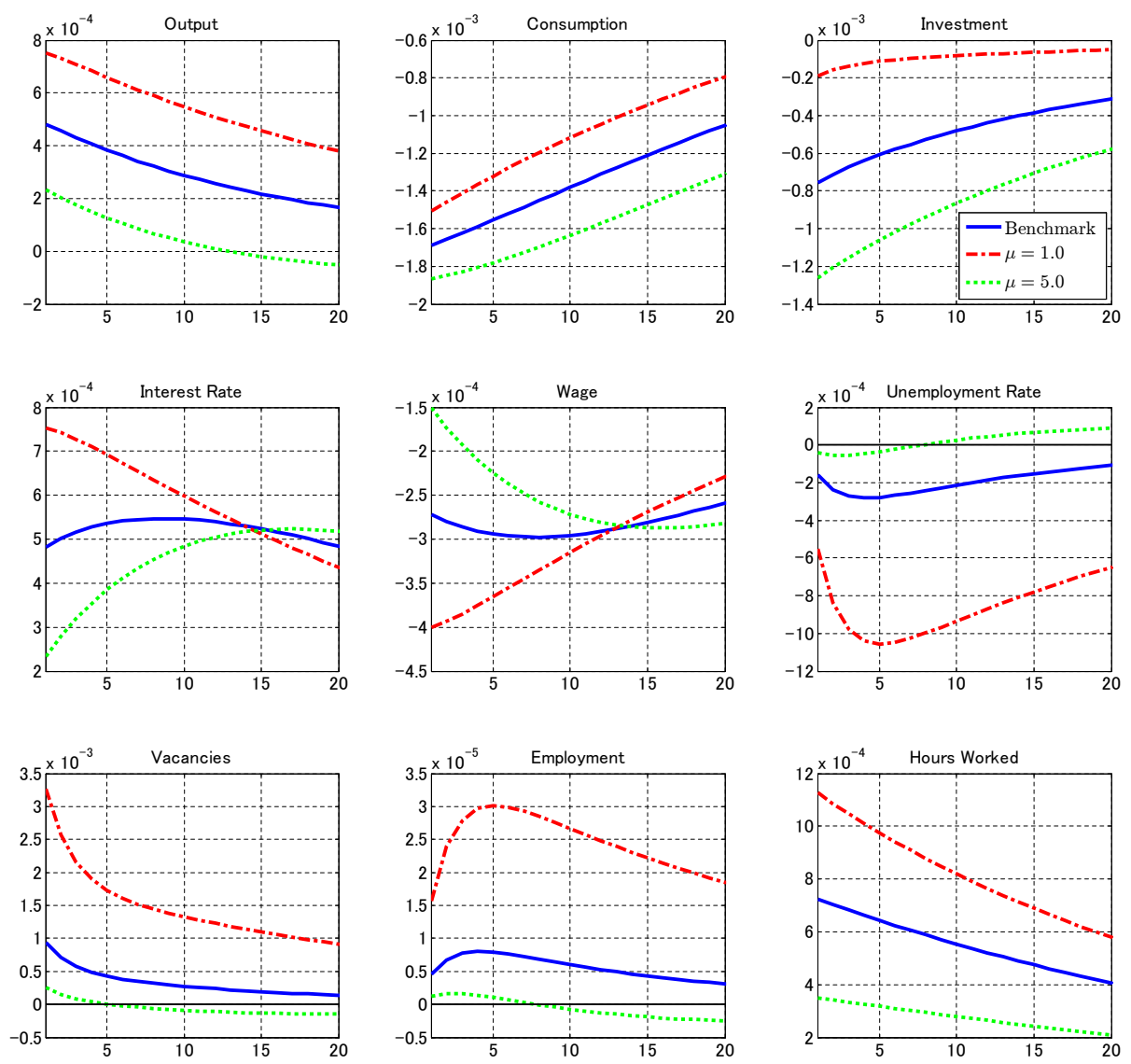

Figure 5: Sensitivity analysis with respect to $\mu$

the disutility of labor increases the marginal costs of production, lowing marginal profits. This discourages firms from posting vacancies, and it becomes harder for an unemployed worker to find a job. It is note that for a high value of $\mu$, the sign of the impact of government spending on unemployment turns to positive.

Finally, we discuss the sensitivity of the results to our choice of the flow value unemployment $z$. This parameter has been the subject of some discussion in the literature on cyclical properties of search and matching models. We now study how the value of $z$ affects responses of labor market variables to the government spending shock. Figure 6 reports the effect of the government spending shock on relevant variables for different values of $z$. While the effect of the government spending shock on output, consumption, investment, interest rates, hours worked, 
the impact of the government spending shock on labor market variables is magnified as $z$ increases. Our finding can be explained by the argument of Hagedorn and Manovskii (2008). Hagedorn and Manovskii (2008) argue that with a high value of $z$, firms make small profits and are more responsive to productivity shock. Thus, a higher value of $z$ increases the volatility of labor market variables in a search and matching model in response to productivity shocks. Our results suggest that this argument is also applied when we analyze the effect of fiscal policies.

\subsection{The role of government spending shocks}

We now study how the degree of persistence of government spending shocks affects our outcomes. Figure 7 displays the impulse responses of relevant variables to a government spending shock for three different values of $\rho_{g}$. Figure 7 shows that effects of the government spending shock on labor market variables depend on the degree of persistence. When the shock is highly persistent, a positive government spending shock reduces the unemployment rate and increases employment. In contrast, when the shock is not highly persistent, it increases the unemployment rate and reduces employment.

This result can be understood by looking at the effect of government spending shock on hours worked and output. When a government spending shock is mildly correlated $\left(\rho_{g}=0.5\right)$, investment falls sharply on the impact. On the other hand, in the case that a government spending shock is persistent, an increase in government spending does not reduce investment as much as in the case in which a shock is not persistent. Thus, persistent changes in government spending generate larger contemporaneous effects on hours worked and output than transient changes. Higher output increases the value of hiring a worker, leading to more vacancy creation. As a result, with persistent shock, an increase in government spending tends to increase employment and reduce unemployment.

\section{Conclusion}

This paper studies effects of fiscal policies on labor market dynamics in the Japanese economy. First, we investigate effects of fiscal expansion on employment, unemployment, worker flow rates, and hours worked by using a structural VAR model. Our empirical analysis demonstrates that the unemployment rate falls and employment rises following an increase in government spending. Since unemployment dynamics is determined by the underlying flows in and out of unemployment, we also study the responses of inflow and outflow rates of unemployment to government spending shock. We find that higher government spending increases the outflow rate of unemployment and reduces the inflow rate. We also investigate the effect of changes in 

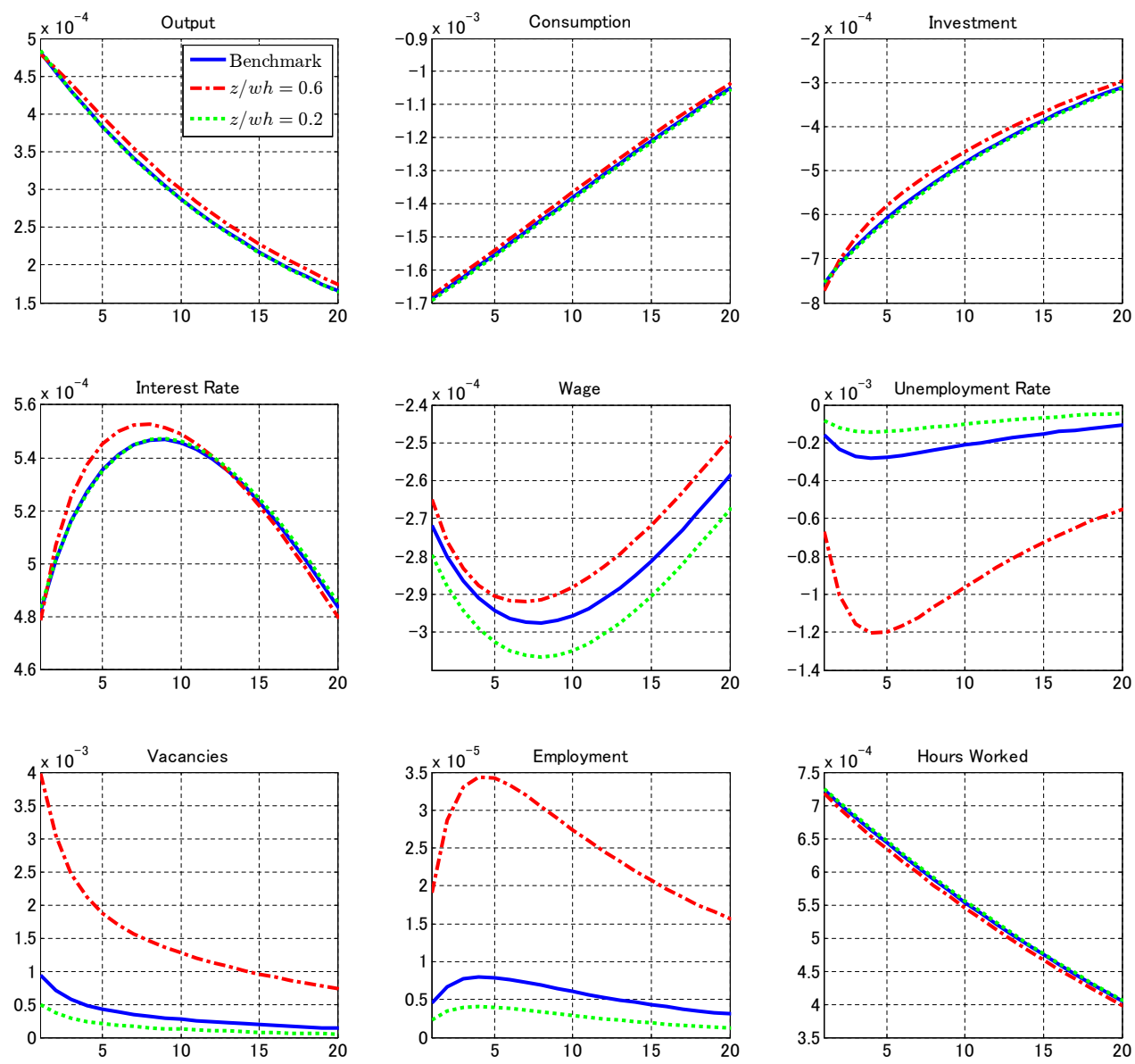

Figure 6: Sensitivity analysis with respect to $z$ 

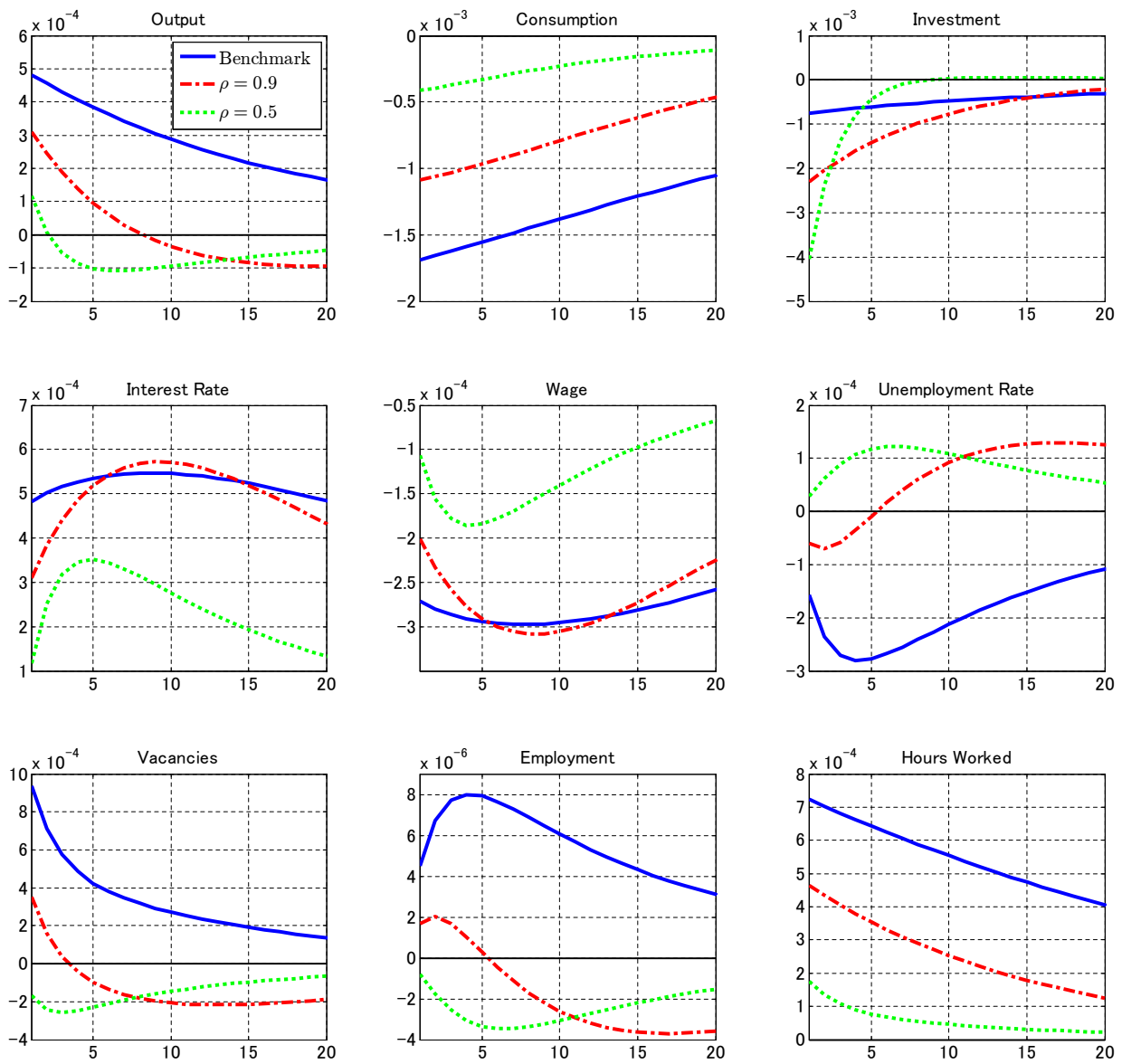

Figure 7: The role of the degree of persistence of government spending shocks 
government spending on other relevant macroeconomic variables and find that their responses to government spending shock are consistent with those in existing studies.

We then develop a stochastic general equilibrium model with labor market frictions. Specifically, we incorporate search and matching frictions into a standard stochastic general equilibrium model and study effects of fiscal expansion on labor market dynamics. The calibrated model can generate a similar pattern of responses of labor market variables to government spending shocks. However, the model fails to re-produce the magnitude of the impact of the government spending shock on labor market variables. Furthermore, similar to the standard general equilibrium model, our model fails to trace responses of consumption and investment to the government spending shock.

A number of important issues remain unanswered. One issue to be considered is the response of private consumption. While our model can consistently capture empirical responses of labor market variables to government spending shocks, it fails to account for the consumption dynamics in the data. The improvement in tracing the actual consumption dynamics is left for our future research: A number of studies consider mechanisms that make consumption responses in theory become consistent with the data (Baxter and King, 1993; Linnemann and Schaubert, 2003; Linnemann, 2006). Incorporating these mechanisms into the model is a fruitful avenue for future research. Also, considering a more realistic fiscal setup with distortionary taxes is an important issue. In our model, the government relies on lump-sum taxes. It is worth

exploring how the economy with a realistic fiscal setup responds to a distortionary fiscal policy, in the form of not just a spending shock but also a tax shock.

\section{References}

[1] Andolfatto, D., 1996. Business cycles and labor market search. American Economic Review $86,112-132$.

[2] Baxter, M., King, R. G., 1993. Fiscal Policy in General Equilibrium. American Economic Review 83(3), 315-34.

[3] Blanchard, O., Perotti, R., 2002. An empirical characterization of the dynamic effects of changes in government spending and taxes on output. Quarterly Journal of Economics117(4),1329-1368.

[4] Brückner, M., Pappa, E., 2012. Fiscal Expansions, Unemployment, and Labor Participation. International Economic Review 53, 1205-1228. 
[5] Burnside, C., Eichenbaum, M., Fisher, J. D. M., 2004. Fiscal shocks and their consequences. Journal of Economic Theory 115,89-117.

[6] Esteban-Pretel, J., Nakajima, R., Tanaka, R., 2010. Japan's Labor Market Cyclicality and the Volatility Puzzle. Graduate Institute for Policy Studies, Mimeo.

[7] Faia, E., Lechthaler, W., Merkl, C., Forthcoming. Fiscal Stimulus and Labor Market Policies in Europe. Journal of Economic Dynamics and Control.

[8] Fueki, T., Fukunaga, I., Ichiue, H., Shirota, T., 2010. Measuring Potential Growth with an Estimated DSGE Model of Japan's Economy. Bank of Japan Working Paper Series No.10-E13.

[9] Galí, J.,David López-Salido, J.,Vallés, J., 2007. Understanding the effects of government spending on consumption. Journal of the European Economic Association 5(1), 227-270.

[10] Hagedorn, M., Manovskii, I., 2008. The cyclical behavior of equilibrium unemployment and vacancies revisited. American Economic Review, 98, 1692-1706.

[11] Hall, R. E., 2005. Employment fluctuations with equilibrium wage stickiness. American Economic Review 95, 50-65.

[12] Hosios, A., 1990. On the Efficiency of Matching and Related Models of Search and Unemployment. Review of Economic Studies 57, 279-298.

[13] Ihori, T., Nakazato, T., Kawade, M., 2002. Japan's Fiscal Policy in the 1990s. Financial Review (63). Policy Research Institute, Ministry of Finance, Government of Japan. 36-68 (In Japanese).

[14] Ihori, T., Nakazato, T., Kawade, M., 2003. Japan's Fiscal Policies in the 1990s. The World Economy 26(3), 325-338.

[15] Iwata, Y., 2009. Fiscal Policy in an Estimated DSGE Model of the Japanese Economy: Do Non-Ricardian Households Explain All? ESRI Discussion Paper Series No. 216.

[16] Kakinaka, M., Miyamoto, H., 2012. Extensive vs. Intensive Margin in Japan. Working Papers EMS-2012-14, Research Institute, International University of Japan.

[17] Kamoi, K., T. Tachibanaki., 2001. On the Effects of Fiscal Policy on Private Demands: A Structural VAR Investigation. Financial Review 55, 165-185 (in Japanese). 
[18] Kano, S., Ohta, M., 2002. An empirical matching function with regime switching: the Japanese case. Discussion Paper No. 967, Institute of Policy and Planning Sciences, University of Tsukuba, Tsukuba, Japan.

[19] Kato, H., 2001. A structural VAR approach to evaluate the effects of fiscal expenditure, National Institute of Population and Social Security Research Discussion Paper (in Japanese).

[20] Kato, R., 2003. Comparison of fiscal multipliers between Japan and the U.S. Bank of Japan Working Paper Series 03-J-4 (In Japanese).

[21] Kawade, M., Ito, A., Nakazato, T., 2004. Effects and Changes of Fiscal Policies after 1990 in Ihori, T., (ed.), Fiscal Deficits of Japan (Nihon no Zaisei Akaji), Iwanami Shoten, Chapter 5: pp. 105-123 (in Japanese).

[22] Kitaura, N., Nagumo, N., Matsuki, T., 2005. Effects of Fiscal Policies on Real GDP in Japan. Financial Review (78). Policy Research Institute, Ministry of Finance, Government of Japan. 131-170 (In Japanese).

[23] Kuroda, S., Yamamoto, I., 2008. Estimating Frisch labor supply elasticity in Japan. Journal of the Japanese and International Economies 22(4), 566-585.

[24] Kuttner, K. N., Posen, A. S., 2002. Fiscal Policy Effectiveness in Japan. Journal of the Japanese and International Economies 16(4), 536-558.

[25] Linnemann, L., 2006. The Effect of Government Spending on Private Consumption: A Puzzle? Journal of Money Credit and Banking 38, 1715-1735.

[26] Linnemann, L., Schaubert, A., 2003. Fiscal Policy in the New Neoclassical Synthesis. Journal of Money Credit and Banking 35, 911-929.

[27] Lubik, T. A., 2009. Estimating a Search and Matching Model of Aggregate Labor Market. Economic Quarterly 95(2), 101-120.

[28] Merz, M., 1995. Search in the labor market and the real business cycle. Journal of Monetary Economics 36, 269-300.

[29] Miyamoto, H., 2011. Cyclical behavior of unemployment and job vacancies in Japan. Japan and the World Economy. 23, 214-25.

[30] Monacelli, T., Perotti, R., Trigari, A., 2010. Unemployment Fiscal Multipliers. Journal of Monetary Economics, 57(5), 531-553. 
[31] Mortensen, D. T., Pissarides, C. A., 1994. Job creation and job destruction in the theory of unemployment. Review of Economic Studies 61, 397-415.

[32] Mortensen, D. T., Nagypál, E., 2007. More on unemployment and vacancy fluctuations. Review of Economic Dynamics 10, 327-347.

[33] Nakazato, T., Konishi, M., 2004. Long Stagnation and Fiscal Policy in 1990s, Hamada, K., Horiuchi, A, Economic and Social research institute. (Eds.). Discussion on Economic Crisis in Japan. Nihon Keizai Shinbun-Sha (In Japanese).

[34] Perotti R., 2007. In Search of the Transmission Mechanism of Fiscal Policy. NBER Macroeconomics Annual 2007, vol.22, pp.169-226.

[35] Petrongolo, B., Pissarides, C. A., 2001. Looking into the Black Box: A Survey of the Matching Function. Journal of Economic Literature 39, 390-431.

[36] Pissarides, C. A., 2000. Equilibrium Unemployment Theory, second ed. MIT Press, Cambridge, MA.

[37] Pissarides, C. A., 2009. The unemployment volatility puzzle: is wage stickiness the answer? Econometrica 77, 1339-1369.

[38] Ramaswamy, R., Rendu, C., 2000. Japan's stagnant nineties: A vector autoregression retrospective. IMF Staff-Papers 47, 259-77.

[39] Ramey, V. A., Shapiro, M. D., 1998. Costly capital reallocation and the effects of government spending. Carnegie Rochester Conference on Public Policy, 145-194.

[40] Shimer, R., 2005. The cyclical behavior of equilibrium unemployment and vacancies. American Economic Review 95, 25-49.

[41] Sugo, T., Ueda, K., 2008. Estimating a dynamic stochastic general equilibrium model for Japan. Journal of the Japanese and International Economies 22(4), 476-502.

[42] Tanaka, H., Kitano, Y., 2002. Macro-economic Effects of Fiscal Policy in OECD Countries. Financial Review (63). Policy Research Institute, Ministry of Finance, Government of Japan. 114-159 (In Japanese).

[43] Yuan, M., Li, W., 2000. Dynamic employment and hours effects of government spending shocks. Journal of Economic Dynamics and Control 24(8), 1233-1263. 


\section{Appendix}

\subsection{Log-linearized model}

The model is log-linearized around the steady-state. The variable with superscript "star" represents its steady-state value and the variable with "hat" represents the log-deviation of a variable from its steady-state. Thus, $\hat{x}_{t}=\log x_{t}-\log x^{*}$.

Log-Linearlized Equilibrium Conditions are as follows:

\section{Labor market:}

$$
\begin{aligned}
\hat{q}_{t} & =-\xi \hat{\theta}_{t} \\
n^{*} \hat{n}_{t} & =-u^{*} \hat{u}_{t} \\
n^{*} \hat{n}_{t} & =(1-s)\left[n^{*} \hat{n}_{t-1}+v^{*} q^{*}\left(\hat{v}_{t-1}+\hat{q}_{t-1}\right)\right] \\
\hat{\theta}_{t} & =\hat{v}_{t}-\hat{u}_{t}
\end{aligned}
$$

Euler equation:

$$
\mathbb{E}_{t}\left[-\sigma \hat{c}_{t+1}+\hat{R}_{t+1}\right]=-\sigma \hat{c}_{t}
$$

Production function:

$$
\hat{y}_{t}=\hat{A}_{t}+\alpha \hat{k}_{t}+(1-\alpha) \hat{h}_{t}
$$

Optimal capital:

$$
\hat{r}_{t}=\hat{A}_{t}+(\alpha-1) \hat{k}_{t}+(1-\alpha) \hat{h}_{t}
$$

\section{Aggregate output and capital:}

$$
\begin{aligned}
& \hat{Y}_{t}=\hat{n}_{t}+\hat{y}_{t} \\
& \hat{K}_{t}=\hat{n}_{t}+\hat{k}_{t}
\end{aligned}
$$

Job creation condition:

$$
\begin{aligned}
-\frac{\kappa}{q^{*}} \hat{q}_{t}= & \beta(1-s) \mathbb{E}_{t} A^{*} k^{* \alpha} h^{* 1-\alpha}\left[\hat{A}_{t+1}+\alpha \hat{k}_{t+1}+(1-\alpha) \hat{h}_{t+1}\right] \\
& -\beta(1-s)\left[w^{*} h^{*} \mathbb{E}_{t}\left(\hat{w}_{t+1}+h_{t+1}\right)+r^{*} k^{*} \mathbb{E}_{t}\left(\hat{r}_{t+1}+\hat{k}_{t+1}\right)+\frac{\kappa}{q^{*}} \mathbb{E}_{t} \hat{q}_{t+1}\right]
\end{aligned}
$$

\section{Wage equation:}

$$
\begin{aligned}
w^{*} h^{*}\left(\hat{w}_{t}+\hat{h}_{t}\right)= & \eta A^{*} k^{* \alpha} h^{* 1-\alpha}\left[\hat{A}_{t}+\alpha \hat{k}_{t}+(1-\alpha) \hat{h}_{t}\right]-\eta r^{*} k^{*}\left(\hat{r}_{t}+\hat{k}_{t}\right) \\
& +\frac{(1-\eta) \Phi_{t} h^{* 1+\mu}}{(1+\mu) c^{*-\sigma}}\left[(1+\mu) \hat{h}_{t}+\sigma \hat{c}_{t}\right]+\eta \kappa \theta^{*} \hat{\theta}_{t}
\end{aligned}
$$


Optimal hours worked:

$$
\hat{A}_{t}+\alpha\left(k_{t}-\hat{h}_{t}\right)-\sigma \hat{c}_{t}=\mu \hat{h}_{t}
$$

\section{Government policy:}

$$
\begin{aligned}
\hat{T}_{t} & =\hat{G}_{t}+z u^{*} \hat{u}_{t} \\
Y^{*} \hat{Y}_{t} & =C^{*} \hat{C}_{t}+I^{*} \hat{I}_{t}+G^{*} \hat{G}_{t}+\kappa v^{*} \hat{v}_{t}
\end{aligned}
$$

\section{Capital evolution:}

$$
\hat{K}_{t+1}=\delta \hat{I}_{t}+(1-\delta) \hat{K}_{t}
$$

